\title{
BMJ Open The association between cytokines and insulin sensitivity in Iraqi immigrants and native Swedes
}

\author{
Ashfaque A Memon, Jan Sundquist, Xiao Wang, Karolina Palmér, \\ Kristina Sundquist, Louise Bennet
}

To cite: Memon AA, Sundquist J, Wang $\mathrm{X}$, et al. The association between cytokines and insulin sensitivity in Iraqi immigrants and native Swedes. BMJ Open 2013;3:e003473. doi:10.1136/bmjopen-2013003473

- Prepublication history and additional material for this paper is available online. To view these files please visit the journal online (http://dx.doi.org/10.1136/ bmjopen-2013-003473)

Received 25 June 2013 Revised 29 October 2013 Accepted 1 November 2013

\section{CrossMark}

Department of Clinical Sciences, Center for Primary Health Care Research, Lund University, Malmö, Sweden and Region Skåne, Sweden

Correspondence to Dr Ashfaque A Memon; ashfaque.memon@med.lu.se

\section{ABSTRACT}

Objectives: To investigate the associations between cytokines and insulin sensitivity in Swedish residents born in Iraq and Swedish residents born in Sweden.

Design: Cross-sectional study.

Settings: Iraqi and Swedish origin residents of Rosengård area of Malmö, aged 45-65 years, were randomly selected from the census register.

Participants/methods: 194 (Iraqi, n=107; Swedish, $n=87$ ) participants agreed to participate in the study. Nineteen participants dropped out (Iraqi, $n=11$; Swedish, $n=8$ ). Participants who had already been diagnosed with type 2 diabetes mellitus (T2DM), those who could not participate in an oral glucose tolerance test and those who had a cold/fever at the time of blood sampling were excluded. In total, serum samples from 135 individuals of Swedish $(n=62)$ and Iraqi $(n=73)$ origin were included. Serum concentrations of a panel of 10 cytokines, comprising interleukin (IL)-1 $\beta$, IL-2, IL-4, IL-5, IL-6, IL-10, IL-12 (p70), IL-13, interferon- $\gamma$ and tumour necrosis factor- $\alpha$ were analysed by Luminex multiplex assay.

Results: In the whole study population, levels of all tested cytokines were inversely associated with insulin sensitivity index (ISI), independent of age, sex, body mass index (BMI), sedentary lifestyle and family history of T2DM $(p \leq 0.05)$. Interestingly, stratification of the study population according to country of birth showed a significant inverse association between all tested cytokines and ISI in the Iraqi-born population $(p \leq 0.01)$. The association was independent of age, sex, BMI, sedentary lifestyle and family history of T2DM. In contrast, with the exception for IL-6 $(p=0.05)$, no other tested cytokine was found to be significantly associated with ISI in the Swedish-born population $(p \geq 0.05)$.

Conclusions: Our results show an association between cytokines and ISI in the Iraqi-born population but not in the Swedish-born population.

\section{INTRODUCTION}

Type 2 diabetes mellitus (T2DM) is a chronic metabolic disorder caused by defects in insulin secretion, insulin action or both. If

\section{Strengths and limitations of this study}

- This is the first study in which the role of cytokines in relation to insulin sensitivity is examined in immigrants from the Middle East as well as in the native population of Swedes.

- The main limitation of our study is the relatively small sample size, which means any ethnic differences need to be confirmed in a larger population. However, it should be noted that the study was conducted as a hypothesis-generating study.

ineffectively controlled, the resulting chronic hyperglycaemia is associated with numerous disabling complications. ${ }^{1}$ The prevalence of T2DM and related conditions is increasing worldwide, and it is estimated that by 2025 , $15 \%$ of the world's population will have T2DM, impaired fasting glucose (IFG) or impaired glucose tolerance (IGT) ${ }^{2}$

In Sweden, the prevalence of T2DM among non-European immigrants is estimated to be 2-3 times higher than among native Swedes. ${ }^{3}$ In addition, previous research has shown that onset of T2DM occurs 10 years earlier in immigrants from the Middle East than native Swedes, and Middle Eastern immigrants diagnosed with T2DM more frequently have a family history of T2DM. ${ }^{4}$

The main mechanisms of insulin resistance in T2DM are oxidative stress, endoplasmic reticulum stress, amyloid deposition in the pancreas, ectopic lipid deposition in the muscle, liver and pancreas, and lipotoxicity and glucotoxicity. ${ }^{5}{ }^{6}$ Although it is difficult to determine which mechanism is the most important, among those with T2DM these processes can be caused by overnutrition. It is important to note, however, that each of these stresses could either induce an inflammatory response or be associated with inflammation. $^{78}$ 
The association between inflammation and insulin resistance and future development of T2DM has been shown previously. ${ }^{9} 10$ The production of tumour necrosis factor (TNF)- $\alpha$ by cells in the adipose tissue of rodents provided early evidence of a link between tissue inflammation and the pathogenesis of insulin resistance and T2DM. ${ }^{11}$ In addition, interleukin (IL)-1 $\beta$ contributes to the glucose-induced impairment of $\beta$-cell function and apoptosis. ${ }^{12}$

Family history and a sedentary lifestyle are highly prevalent risk factors for T2DM in immigrants from the Middle East. ${ }^{4}{ }^{13}$ Obesity is another major risk factor for T2DM that is also highly prevalent among immigrants from the Middle East. ${ }^{13}$ Obesity is associated with low-grade chronic inflammation, which activates the innate immune system. This activation leads to the release of proinflammatory cytokines such as TNF- $\alpha$, IL-1 $\beta$ and IL- 6 , which disrupt insulin homeostasis by blocking major anabolic cascades downstream of insulin signalling. ${ }^{10}$ Elevated levels of proinflammatory cytokines may thus characterise the early preclinical stages of T2DM. ${ }^{14-16}$

Even though the association between high levels of cytokines and insulin resistance has been well studied, few studies have been performed to elucidate the roles of inflammatory markers in various ethnic groups. In one such study from the USA, circulating TNF- $\alpha$ levels were found to differ according to ethnicity, with Hispanics having the highest levels and African Americans the lowest. ${ }^{17}$

Characterising inflammatory markers in the population groups at highest risk of developing T2DM is important in the prediction of disease onset and the evaluation of strategies for disease prevention. The aim of this study was to investigate the relationship between cytokines and insulin sensitivity in two ethnically different groups: residents of the Swedish city of Malmö who were born in Sweden and Iraq. To our knowledge, this is the first study of its kind in which profiles of as many as 10 cytokines were analysed in two ethnic groups.

\section{MATERIAL AND METHODS \\ Subjects}

Male and female residents in the Rosengård residential area of Malmö, aged 45-65 years and born in Sweden (Swedes) or Iraq (Iraqis), were randomly selected from the census register. We chose the ages $45-65$ years since that was the age group of the non-retired population with the highest probability of identifying individuals with prediabetes or diabetes, since the prevalence of diabetes increases with age. In total, 296 individuals were invited to participate. The study was performed according to the declaration of Helsinki. ${ }^{18}$ Written informed consent was given by all the participants in the study after full explanation of the purpose and nature of all procedures used.

\section{Clinical variable assessment}

Body mass index (BMI) was calculated as weight $(\mathrm{kg})$ divided by height $\left(\mathrm{m}^{2}\right)$. Abdominal obesity was defined as waist circumference of $\geq 102 \mathrm{~cm}$ for men and $\geq 88 \mathrm{~cm}$ for women. ${ }^{19}$ Leisure time physical activity was classified into four categories as described previously. ${ }^{13}$ Individuals in categories 2-4 were considered physically active while those in category 1 were considered sedentary. Systolic and diastolic blood pressure was measured twice in the supine position after $5 \mathrm{~min}$ rest. The mean of the two measurements was calculated.

A standard of $75 \mathrm{~g}$ oral glucose tolerance test (OGTT) was performed and blood glucose was measured in blood samples collected at $0,30,60$ and $120 \mathrm{~min}$ by a HemoCue photometer (HemoCue AB, Ängelholm, Sweden) ${ }^{20}$ Insulin sensitivity index (ISI) was calculated from the OGTT data as described previously. ${ }^{21}$ Participants were asked not to eat after 22:00 the day before the sample collection. Normal glucose tolerance (NGT) was defined as a fasting plasma glucose $(0 \mathrm{~h}$ sample) level of $<6.1 \mathrm{mmol} / \mathrm{L}$ and a plasma glucose level of $<7.8 \mathrm{mmol} / \mathrm{L} 2 \mathrm{~h}$ after having been given $75 \mathrm{~g}$ glucose in the OGTT. ${ }^{22}$ IFG was defined as a fasting plasma glucose level of $\geq 6.1 \mathrm{mmol} / \mathrm{L}$ and $<7 \mathrm{mmol} /$ $\mathrm{L}$ and a $2 \mathrm{~h}$ glucose level of $<7.8 \mathrm{mmol} / \mathrm{L}$. An IGT test was defined as either a fasting plasma glucose level of $\geq 6.1 \mathrm{mmol} / \mathrm{L}$ and $<7 \mathrm{mmol} / \mathrm{L}$ and/or a $2 \mathrm{~h}$ glucose level of $\geq 7.8 \mathrm{mmol} / \mathrm{L}$ and $<11.1 \mathrm{mmol} / \mathrm{L}$. T2DM was defined as fasting plasma glucose level of $\geq 7 \mathrm{mmol} / \mathrm{L}$ and/or OGTT of $\geq 11.1 \mathrm{mmol} / \mathrm{L} .{ }^{22}$ Hyperglycaemia was defined as patients with IFG, IGT or T2DM. Serum insulin levels were determined using the radioimmunoassay technique (Access Ultrasensitive Insulin, Beckman Coulter, USA) ${ }^{23}$

Cholesterol and triglycerides were analysed using enzymatic methods, whereas high-density lipoprotein (HDL)-cholesterol was measured after isolation of lowdensity lipoprotein (LDL) and very low-density lipoprotein (VLDL; Boehringer Mannheim GmbH, Germany) and LDL cholesterol was analysed using Friedewald's method. ${ }^{24}$

$\mathrm{C}$ reactive protein (CRP) was measured by a commercial kit from Roche diagnostics, according to the manufacturer's instructions.

\section{Sample preparation and quantification of cytokines}

Samples were collected into a $3.5 \mathrm{~mL}$ serum separating tube and were allowed to clot for $1 \mathrm{~h}$ at room temperature. They were then centrifuged for $10 \mathrm{~min}$ at $4^{\circ} \mathrm{C}$ and serum was aliquoted and stored at $-80^{\circ} \mathrm{C}$ for further use. The Bio-Plex Precision Pro Human Cytokine 10-Plex Panel (Bio-Rad Inc, Hercules, California, USA), a high-sensitivity Luminex-based magnetic bead assay, was used to quantify IL-1 $\beta$, IL-2, IL-4, IL-5, IL-6, IL-10, IL-12 (p70), IL-13, interferon (IFN)- $\gamma$ and TNF- $\alpha$ in serum according to the manufacturer's instructions. In brief, samples were diluted 1:4 in the sample diluent provided with the kit and incubated with magnetic beads coupled to specific antibodies. Cytokines were detected with premixed detection antibody. Beads were read on a Bio-Plex Suspension Array System and the data were analysed using Bio-Plex Manager software (V.4.0). Absolute concentrations were measured from a 
standard curve generated from eight serially diluted standards provided with the kit. Each sample was analysed in duplicate. Values are presented in $\mathrm{pg} / \mathrm{ml}$. Each run included controls of known concentration for each cytokine and a blank. Detection limits for IL-1 $\beta$, IL-2, IL-4, IL-5, IL-6, IL-10, IL-12 (p70), IL-13, IFN- $\gamma$ and TNF- $\alpha$ were $0.14,0.6,0.16,0.87,0.44,0.37,0.13,0.31$, 0.3 and $0.13 \mathrm{pg} / \mathrm{mL}$, respectively. Interassay coefficient of variation was between 6.2 and 13.3 (values were calculated from six different experiments).

\section{Statistical analysis}

Differences in sample characteristics between Swedish-born participants and first-generation immigrants from Iraq were tested using Student's t test for continuous variables, $\chi^{2}$ tests for dichotomous variables and the Wilcoxon rank-sum test for the variables with a non-normal distribution (table 1). Distribution of all cytokines is presented with median and IQR and tested with the Wilcoxon rank-sum test (table 2). Tables 1 and 2 were also adjusted for age, sex and BMI and adjusted $\mathrm{p}$ values were calculated using linear regression for continuous variables, logistic regression for dichotomous variables, ordered logistic regression for normal/ impaired/T2D and rank analysis of covariance ${ }^{25}$ for variables with non-normal distribution.

Linear regression was used to examine the associations between cytokine levels and ISI. Natural log transformation of ISI was used to obtain an approximately normal distribution. IL-5, IL-12 (p70), IFN- $\gamma$ and TNF- $\alpha$ were transformed with a natural $\log$ function due to their highly skewed distribution. IL-6 was dichotomised into below detection limit $(<0.44 \mathrm{pg} / \mathrm{mL})$ values and above detection limits $(\geq 0.44)$, due to nearly $50 \%$ of values being below detection limit. It was possible to include the other cytokines untransformed. First, univariate analysis was performed to assess the association of each cytokine with ISI in the whole sample. Thereafter, multivariate linear regression was performed with ISI as the dependent variable and with adjustment for BMI and/or waist circumference, age, sex, sedentary lifestyle and family history of T2DM (table 3). All analyses were then stratified by country of birth to examine whether the associations differed between individuals born in Sweden and those born in Iraq (table 4). The associations were also examined by including an interaction term between each cytokine and country of birth in the multivariate linear regression model (see online supplementary table). To test the robustness of the results from the regression models, we repeated the analysis with dichotomisation of all the cytokines. STATA V.12 (Stata Corp LP) was used for all statistical analyses.

\section{RESULTS}

\section{Baseline characteristics of the study population}

Of the total number of invited participants, 194 (Iraqi, $\mathrm{n}=107$; Swedish, $\mathrm{n}=87$ ) agreed to participate and were included in the study between 1 February and 31 March 2010. Patients who had already been diagnosed with T2DM and those who could not participate in an OGTT (Iraqi, n=24; Swedish, n=13) were excluded from the study. Nineteen participants dropped out (Iraqi, $\mathrm{n}=11$; Swedish, $n=8)$. Those who had a cold/fever $(n=3)$ at the time of blood sampling were not included in the analyses. In total, 135 individuals were included (Iraqi, $\mathrm{n}=73$; Swedes, $\mathrm{n}=62$ ) in the analyses. Table 1 shows the anthropometric and metabolic characteristics of the study participants born in Iraq and Sweden. Consistent with earlier reported data from the same populationbased study, ${ }^{13}$ median ISI was higher in the Swedes than in the Iraqis. Swedes were older and had lower BMI than Iraqis. Mean HDL levels were higher in Swedes than in Iraqis, whereas triglyceride levels were higher in Iraqis than in Swedes. The prevalence of family history of T2DM was significantly higher in Iraqis than in Swedes. Mean systolic and diastolic blood pressures were higher in Swedes than in Iraqis. Iraqis had higher levels of $2 \mathrm{~h}$ glucose levels than Swedes. However, after adjusting for age, sex and BMI, differences in ISI and triglycerides between Iraqis and Swedish did not remain significant. There were no significant differences in sex, waist circumference, sedentary lifestyle, NGT, IGT or T2DM, fasting glucose, fasting serum insulin, glycated haemoglobin, LDL, triglycerides, C-peptide and levels of CRP between the two groups (table 1). Sixty-four per cent Iraqi and 65\% Swedes had NGT, 30\% Iraqis and $31 \%$ Swedes had IGT and 5\% each were diagnosed with T2DM in Swedes and Iraqis.

\section{Expression of cytokines}

Table 2 shows expressions of cytokines (median and IQRs) in the whole population and in the two ethnic groups. There were no significant differences in median values between study participants born in Iraq and Sweden before as well as after adjusting for age, sex and BMI.

\section{Association between cytokines and ISI}

In the overall population, univariate analysis showed that, with the exception of IL-12 ( $p 70 ; p=0.07)$, the levels of all analysed cytokines had significant $(\mathrm{p} \leq 0.05)$ inverse associations with ISI (table 3). Interestingly, after adjusting for age, sex, BMI, sedentary lifestyle and family history of T2DM, levels of all analysed cytokines remained inversely associated with ISI $(p \leq 0.05$; table 3$)$. Stratification of the data according to ethnicity showed strong inverse associations between levels of IL-1 $\beta$, IL-2, IL-4, IL-5, IL-10, IL-12 (p70), IL-13 and IFN- $\gamma(\mathrm{p} \leq 0.02)$ and ISI in Iraqis (table 4). After adjustment for age, sex, BMI, sedentary lifestyle and family history of T2DM, all 10 tested cytokines remained significantly associated with ISI in the Iraqi population $(p \leq 0.01$; table 4). Subanalysis of IL-6 and TNF- $\alpha$ by separately entering age, sex, BMI, sedentary life style and family history of T2DM in the model showed that sedentary life style and family history of T2DM were associated with ISI, IL-6 and 
Table 1 Baseline anthropometric and metabolic characteristics of the study population by country of birth

\begin{tabular}{|c|c|c|c|c|}
\hline Covariate & Iraq $(n=73)$ & Sweden $(n=62)$ & p Value & Adjusted $\mathrm{p}$ value ${ }^{*}$ \\
\hline Sex (female/male) $\dagger$ & $48 / 52$ & $45 / 55$ & 0.75 & 0.63 \\
\hline Age (years) $\ddagger$ & $54(5.9)$ & $57(5.4)$ & 0.01 & 0.002 \\
\hline BMI $\left(\mathrm{kg} / \mathrm{m}^{2}\right) \ddagger$ & $29(4.1)$ & $27(4.4)$ & 0.007 & 0.002 \\
\hline Waist circumference $(\mathrm{cm}) \ddagger \S$ & $98(12)$ & 97 (12) & 0.87 & 0.54 \\
\hline Sedentary lifestyle (yes/no)† & $71 / 29$ & $57 / 43$ & 0.10 & 0.20 \\
\hline Family history (yes/no)† & $59 / 41$ & $25 / 75$ & 0.0002 & 0.004 \\
\hline Systolic BP $(\mathrm{mm} \mathrm{Hg}) \ddagger$ & 129 (19) & $141(22)$ & 0.0008 & 0.004 \\
\hline Diastolic BP $(\mathrm{mm} \mathrm{Hg}) \ddagger$ & $81(12)$ & $88(12)$ & 0.003 & 0.008 \\
\hline ISI⿹ & $84(56)$ & $104(77)$ & 0.04 & 0.51 \\
\hline NormoglycaemialIFG or IGTIT2D & $64 / 30 / 5$ & $65 / 31 / 5$ & 0.99 & 0.89 \\
\hline Fasting glucose $(\mathrm{mmol} / \mathrm{L}) \ddagger$ & $5.7(0.9)$ & $5.8(0.9)$ & 0.43 & 0.53 \\
\hline $2 \mathrm{~h}$ Glucose $(\mathrm{mmol} / \mathrm{L}) \ddagger$ & $7.1(2.8)$ & $6(2.6)$ & 0.02 & 0.02 \\
\hline Serum insulin $(\mathrm{pmol} / \mathrm{L}) \dagger$ & $8(5)$ & $7(4)$ & 0.22 & 0.79 \\
\hline HbA1c (\%) $\ddagger^{* *}$ & $4.9(0.6)$ & $4.9(0.8)$ & 0.95 & 0.63 \\
\hline LDL (mmol/L)‡ & $3.5(0.8)$ & $3.7(1.0)$ & 0.36 & 0.61 \\
\hline $\mathrm{HDL}(\mathrm{mmol} / \mathrm{L}) \ddagger$ & $1.1(0.3)$ & $1.3(0.5)$ & 0.001 & 0.002 \\
\hline Triglycerides $(\mathrm{mmol} / \mathrm{L}) \uparrow$ & $1.4(1.0)$ & $1.0(1.1)$ & 0.02 & 0.24 \\
\hline C-peptide $(\mathrm{mmol} / \mathrm{L})$ q & $0.6(0.3)$ & $0.6(0.3)$ & 0.65 & 0.08 \\
\hline $\mathrm{C}$ reactive protein $(\mathrm{mg} / \mathrm{L}) \ddagger$ & $3.6(2.9)$ & $3.4(2.7)$ & 0.71 & 0.74 \\
\hline
\end{tabular}

${ }^{*}$ Adjusted for sex, age and BMI.

†Sex, sedentary lifestyle, hyperglycaemia and family history are presented as percentages.

$\ddagger$ Age, BMI, cholesterol, LDL, HDL, HbA1c, systolic and diastolic BP, waist circumference, C reactive protein, fasting glucose and $2 \mathrm{~h}$ glucose are presented as the mean and SD.

§Adjusted for sex and age.

ๆISI, triglycerides and C-peptide are presented as the median and IQR.

${ }^{* *} \mathrm{HbA} 1 \mathrm{c}$ is presented as mean in IFCC units (NGSP units).

BMI, body mass index; BP, blood pressure; HDL, high-density lipoprotein; HbA1c; glycated haemoglobin; IGT, impaired glucose tolerance;

IFG, impaired fasting glucose; ISI, insulin sensitivity index; LDL, low-density lipoprotein; T2D, type 2 diabetes.

TNF- $\alpha$ (data not shown). In contrast, in the Swedes, no cytokine, except IL-6 ( $\mathrm{p}=0.05)$, was significantly associated with ISI in the univariate analysis and after adjusting for age, sex, BMI, sedentary life style and family history of T2DM (table 4). Changing the variable BMI to the variable waist circumference gave almost identical $p$ values and $\beta$-values (data not shown). Interestingly, not only did the $p$ values differ between Iraqi and Swedes, but all $\beta$-values were also higher in Iraqis than in Swedes, even after adjusting for age, sex, BMI, sedentary life style and family history of T2DM (eg, $\beta=-0.73$ for TNF- $\alpha$ in Iraqis compared with -0.26 in Swedes, table 4). We also repeated the analysis with all cytokines dichotomised with the 75th centile as cut-off in the regression models; the results remained almost identical (data not shown). In the interaction tests, we found no significant difference in associations between Iraqis and Swedish participants (see online supplementary table).

Table 2 Concentration of cytokine levels, stratified by country of birth

\begin{tabular}{|c|c|c|c|c|c|}
\hline \multirow[b]{2}{*}{ Cytokines* } & \multirow{2}{*}{$\frac{\text { All }(n=135)}{\text { Median (IQR) }}$} & \multirow{2}{*}{$\frac{\text { Iraq }(n=73)}{\text { Median (IQR) }}$} & \multicolumn{3}{|l|}{ Sweden $(n=62)$} \\
\hline & & & Median (IQR) & p Valuet & Adjusted $\mathrm{p}$ valuef \\
\hline IL-1 $\beta$ & $0.94(0.77)$ & $0.94(0.98)$ & $0.94(0.67)$ & 0.78 & 0.88 \\
\hline IL-2 & $6.25(4.93)$ & $5.78(4.83)$ & $6.55(4.93)$ & 0.72 & 0.66 \\
\hline IL-4 & $0.69(0.58)$ & $0.72(0.72)$ & $0.69(0.47)$ & 0.44 & 0.70 \\
\hline IL-5 & 7.96 (6.95) & $8.28(7.82)$ & 7.95 (6.78) & 0.47 & 0.43 \\
\hline IL-6 & $1.26(6.38)$ & $1.62(6.76)$ & $0(5.22)$ & 0.32 & 0.40 \\
\hline IL-10 & $6.89(6.58)$ & $7.26(7.15)$ & $6.41(5.2)$ & 0.51 & 0.68 \\
\hline IL-12 (p70) & $1.14(1.14)$ & $1.21(1.15)$ & $1.04(1.10)$ & 0.76 & 0.82 \\
\hline IL-13 & $2.05(1.54)$ & $2.06(1.66)$ & $2.01(1.43)$ & 0.39 & 0.59 \\
\hline $\mathrm{IFN}-\gamma$ & $2.81(2.48)$ & $2.79(2.6)$ & $2.82(2.11)$ & 0.47 & 0.47 \\
\hline TNF- $\alpha$ & $0.65(0.68)$ & $0.67(0.78)$ & $0.65(0.64)$ & 0.34 & 0.38 \\
\hline
\end{tabular}

${ }^{*}$ Values are shown in $\mathrm{pg} / \mathrm{mL}$

tp Value for test between Iraq and Sweden.

$\ddagger$ Adjusted for sex, age and BMI.

BMI, body mass index; IFN- $\gamma$, interferon- $\gamma$; IL, interleukin; TNF- $\alpha$, tumour necrosis factor- $\alpha$. 
Table 3 Multivariate linear regression of the whole study population with logarithmic insulin sensitivity index as the dependent variable and cytokine level as the exposure

\begin{tabular}{|c|c|c|c|c|c|c|}
\hline \multirow[b]{2}{*}{ Cytokines $†$} & \multicolumn{3}{|c|}{ Unadjusted } & \multicolumn{3}{|c|}{ Adjusted* } \\
\hline & $\overline{\boldsymbol{\beta}}$ & p Value & $95 \% \mathrm{Cl}$ & $\overline{\boldsymbol{\beta}}$ & p Value & $95 \% \mathrm{Cl}$ \\
\hline IL-1 $\beta$ & -0.24 & $<0.01$ & -0.39 to -0.08 & -0.23 & 0.01 & -0.39 to -0.07 \\
\hline IL-2 & -0.04 & $<0.01$ & -0.07 to -0.01 & -0.04 & $<0.01$ & -0.07 to -0.02 \\
\hline IL-4 & -0.30 & $<0.01$ & -0.50 to -0.11 & -0.27 & 0.01 & -0.48 to -0.06 \\
\hline IL-5 & -0.16 & 0.02 & -0.30 to -0.02 & -0.20 & 0.01 & -0.35 to -0.06 \\
\hline IL-6 & -0.27 & 0.01 & -0.46 to -0.08 & -0.26 & 0.01 & -0.45 to -0.07 \\
\hline IL-10 & -0.03 & 0.01 & -0.05 to -0.01 & -0.03 & $<0.01$ & -0.05 to -0.01 \\
\hline IL-12 (p70) & -0.21 & 0.07 & -0.44 to 0.02 & -0.28 & 0.02 & -0.51 to -0.04 \\
\hline IL-13 & -0.14 & $<0.01$ & -0.22 to -0.05 & -0.12 & 0.01 & -0.21 to -0.03 \\
\hline IFN- $\gamma$ & -0.21 & 0.03 & -0.41 to -0.02 & -0.20 & 0.05 & -0.40 to 0.00 \\
\hline TNF- $\alpha$ & -0.32 & 0.05 & -0.65 to 0.00 & -0.41 & 0.03 & -0.77 to -0.04 \\
\hline
\end{tabular}

*IL-1 1 , IL-2, IL-4, IL-10 and IL-13 were used untransformed; IL-5, IL-12 (p70), IFN- $\gamma$ and TNF- $\alpha$ were In-transformed; and IL-6 was dichotomised into below $(<0.44 \mathrm{pg} / \mathrm{mL})$ and above $(\geq 0.44)$ detection limits.

tCovariates in the models: age, sex, BMI, sedentary lifestyle and family history.

$\mathrm{BMI}$, body mass index; IFN- $\gamma$, interferon- $\gamma$; IL, interleukin; TNF- $\alpha$, tumour necrosis factor- $\alpha$.

\section{DISCUSSION}

For the first time, the expression of a panel of 10 cytokines in Swedish-born and Iraqi-born populations and their associations with insulin sensitivity was investigated. We found that levels of all 10 cytokines included in this study were strongly associated with lower insulin sensitivity in Iraqis, after controlling for age, sex, BMI, sedentary lifestyle and family history of T2DM. These findings were not observed among the Swedes.

Ethnic differences do exist in the prevalence of T2DM and its complications ${ }^{26}$; however, no previous study has investigated the inflammatory response in Middle Eastern immigrants as well as in native Scandinavians. The prevalence of T2DM in the immigrant population in Sweden has been shown to be higher than that in native Swedes. ${ }^{3}$ A large proportion of the immigrants in Sweden are from the Middle East, and Iraqis constitute one of the largest immigrant group in Sweden and the largest immigrant population living in Malmö. Consistent with our results, a previous study of patients born in the Middle East and Sweden suggests that patients born in the Middle East have earlier T2DM onset, higher BMI and higher prevalence of family history of T2DM than Swedish-born patients with T2DM. ${ }^{4}$

Low-grade systemic inflammation results in insulin resistance, to which pancreatic islets respond by enhancing their cell mass and thereby their insulin secretory activity. However, exhaustion of this mechanism leads to insulin deficiency and ultimately T2DM. ${ }^{27}$ Elevated levels of cytokines such as IL-6 and TNF- $\alpha$ have been associated with T2DM in other ethnic groups. ${ }^{28}$ As described previously in the same population, Iraqis have a lower insulin sensitivity than Swedes. ${ }^{13}$ However, it is not known whether cytokines have any role in this difference. Our results show that high levels of all cytokines analysed in this study (IL-1 $\beta$, IL-2, IL-4, IL-5, IL-6, IL-10, IL-12 (p70), IL-13, IFN- $\gamma$ and TNF- $\alpha$ ) were independently associated with lower insulin sensitivity in immigrants from Iraq, whereas high levels of only IL-6 were found to be associated with lower insulin sensitivity in Swedes. Obesity increases proinflammatory cytokine levels in the circulation and peripheral tissues. Iraqi participants had higher BMI values than the Swedes. ${ }^{13}$ However, the association between cytokines and insulin resistance in the Iraqi population was found to be independent of BMI, suggesting that the association between cytokines and insulin resistance was not due to the higher BMI values in the Iraqis. There was no difference in waist circumference between the two groups.

It has been reported that it is not the general adiposity but rather visceral fat that is associated with the incidence of prediabetes and T2DM. ${ }^{29}$ In fact, ectopic fat deposition in the abdominal viscera has been shown to be a more important mediator of diabetes development than the total fat mass in obese individuals. ${ }^{30}$ High visceral and hepatic fat levels have been associated with higher levels of IL- $6{ }^{31}$ and IL- $8,{ }^{32}$ respectively. We did not measure visceral or hepatic fat in our study population to prove this assumption. However, we adjusted our data with waist circumference used as a proxy for visceral fat, but it did not explain the association between insulin resistance and cytokines in Iraqis (data not shown). Impaired glucose levels have been associated with higher level of inflammation, which eventually leads to insulin resistance. ${ }^{33}$ Source of increased circulating levels of cytokines in T2DM seems to originate from non-circulating cells such as adipocytes and endothelial cells. ${ }^{34}$ Furthermore, higher glucose levels increases the secretion of cytokines from cultured human endothelial cells. ${ }^{35}$ Iraqis are known to have higher IGT levels. Therefore, it is possible that the major source of secreted cytokines in Iraqis may not be adipocytes and it can be speculated that the association between cytokines and insulin resistance in Iraqis is due to higher blood glucose level which leads to increase in inflammatory process, independent of obesity.

The main limitation of our study is the small sample and few observations, which means that the results need 


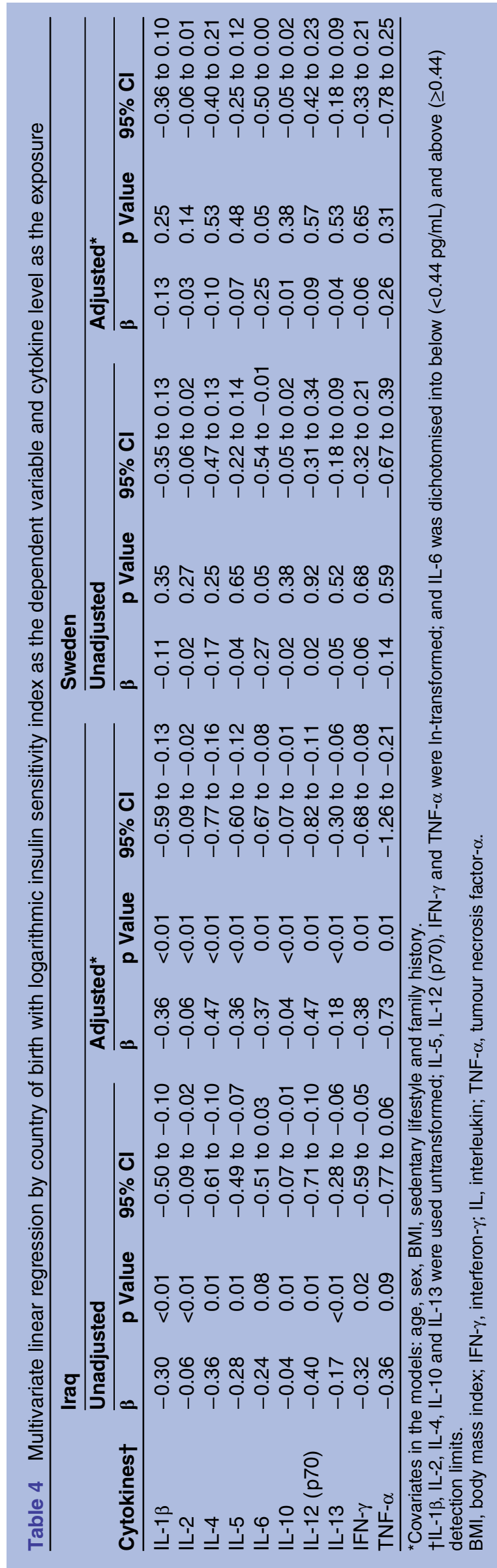

to be confirmed in a larger population. However, it should be noted that it was conducted as a hypothesisgenerating study.

In conclusion, we have for the first time examined cytokine levels in Iraqi-born and Swedish-born residents of Sweden in relation to insulin sensitivity. We found an inverse association between cytokines and insulin sensitivity in Iraqis but not in Swedes. This association was independent of sex, BMI, age, sedentary lifestyle or prevalence of family history of T2DM. However, further investigations on larger population samples are required to establish potential differences in associations between population groups.

Acknowledgements The authors would like to thank Anna Hedelius for excellent technical support and Stephen Gilliver for critical reading of the article.

Contributors AAM, JS, KS and LB conceived and designed the study. AAM and XW performed the experiments. AAM, JS, KP, KS and LB performed the data analysis and interpretation. AAM, JS, XW, KP, KS and LB drafted and revised the article, and approved the final version.

Funding The study was supported by ALF funding.

Competing interests FoU grants from Region Skåne and a grant from the Swedish Society of Medicine awarded to LB. JS and KS were funded by grants by the Swedish Research Council and by an ALF project grant, Lund, Sweden.

Ethics approval The ethical committee at Lund University approved the study (approval no. 2009/36).

Provenance and peer review Not commissioned; externally peer reviewed.

Data sharing statement No additional data are available.

Open Access This is an Open Access article distributed in accordance with the Creative Commons Attribution Non Commercial (CC BY-NC 3.0) license, which permits others to distribute, remix, adapt, build upon this work noncommercially, and license their derivative works on different terms, provided the original work is properly cited and the use is non-commercial. See: http:// creativecommons.org/licenses/by-nc/3.0/

\section{REFERENCES}

1. Tripathy $D$, Chavez $A O$. Defects in insulin secretion and action in the pathogenesis of type 2 diabetes mellitus. Curr Diab Rep 2010;10:184-91.

2. Kaul K, Tarr JM, Ahmad SI, et al. Introduction to diabetes mellitus. Adv Exp Med Biol 2012;771:1-11.

3. Wandell PE, Johansson SE, Gafvels C, et al. Estimation of diabetes prevalence among immigrants from the Middle East in Sweden by using three different data sources. Diabetes Metab 2008;34:328-33.

4. Glans F, Elgzyri T, Shaat N, et al. Immigrants from the Middle-East have a different form of type 2 diabetes compared with Swedish patients. Diabet Med 2008;25:303-7.

5. Harding HP, Ron D. Endoplasmic reticulum stress and the development of diabetes: a review. Diabetes 2002;51(Suppl 3): S455-61.

6. Weir GC, Bonner-Weir S. Five stages of evolving beta-cell dysfunction during progression to diabetes. Diabetes 2004;53(Suppl 3):S16-21.

7. Donath MY, Schumann DM, Faulenbach M, et al. Islet inflammation in type 2 diabetes: from metabolic stress to therapy. Diabetes Care 2008;31(Suppl 2):S161-4.

8. Hotamisligil GS, Erbay E. Nutrient sensing and inflammation in metabolic diseases. Nat Rev Immunol 2008;8:923-34.

9. Donath $\mathrm{MY}$, Boni-Schnetzler $\mathrm{M}$, Ellingsgaard $\mathrm{H}$, et al. Islet inflammation impairs the pancreatic beta-cell in type 2 diabetes. Physiology (Bethesda) 2009;24:325-31.

10. Shoelson SE, Lee J, Goldfine AB. Inflammation and insulin resistance. J Clin Invest 2006;116:1793-801. 
11. Hotamisligil GS, Shargill NS, Spiegelman BM. Adipose expression of tumor necrosis factor-alpha: direct role in obesity-linked insulin resistance. Science 1993;259:87-91.

12. Maedler K, Sergeev P, Ris F, et al. Glucose-induced beta cell production of IL-1beta contributes to glucotoxicity in human pancreatic islets. J Clin Invest 2002;110:851-60.

13. Bennet L, Johansson SE, Agardh CD, et al. High prevalence of type 2 diabetes in Iraqi and Swedish residents in a deprived Swedish neighbourhood-a population based study. BMC Public Health 2011;11:303.

14. Festa A, D'Agostino R Jr, Tracy RP, et al. Elevated levels of acute-phase proteins and plasminogen activator inhibitor-1 predict the development of type 2 diabetes: the insulin resistance atherosclerosis study. Diabetes 2002;51:1131-7.

15. Meigs JB, Hu FB, Rifai N, et al. Biomarkers of endothelial dysfunction and risk of type 2 diabetes mellitus. JAMA 2004;291:1978-86.

16. Pradhan AD, Manson JE, Rifai N, et al. C-reactive protein, interleukin 6 , and risk of developing type 2 diabetes mellitus. JAMA 2001;286:327-34.

17. Olson NC, Callas PW, Hanley AJ, et al. Circulating levels of TNF-alpha are associated with impaired glucose tolerance, increased insulin resistance, and ethnicity: the Insulin Resistance Atherosclerosis Study. J Clin Endocrinol Metab 2012;97:1032-40.

18. WMA. Declaration of Helsinki-ethical principals of medical research involving human subjects. 2008.

19. Yusuf $S$, Hawken S, Ounpuu $S$, et al. Effect of potentially modifiable risk factors associated with myocardial infarction in 52 countries (the INTERHEART study): case-control study. Lancet 2004;364:937-52.

20. von Schenck H, Falkensson M, Lundberg B. Evaluation of 'HemoCue, a new device for determining hemoglobin. Clin Chem 1986;32:526-9.

21. Matsuda M, DeFronzo RA. Insulin sensitivity indices obtained from oral glucose tolerance testing: comparison with the euglycemic insulin clamp. Diabetes Care 1999;22:1462-70.

22. World Health Organization WHO. Definition, diagnosis and classification of diabetes mellitus and its complications: Report of a WHO consultation. Part 1: diagnosis and classification of diabetes mellitus. Geneva: World Health Organization, 1999.
23. Thorell JLS. Radioimmunoassay and related techniques. ST Louis: The CV Mosby Company, 1978:205-21.

24. Friedewald WT, Levy RI, Fredrickson DS. Estimation of the concentration of low-density lipoprotein cholesterol in plasma, without use of the preparative ultracentrifuge. Clin Chem 1972;18:499-502.

25. LaVange LM, Koch GG. Rank score tests. Circulation 2006; 114:2528-33.

26. Abate N, Chandalia M. The impact of ethnicity on type 2 diabetes. $J$ Diabetes Complications 2003;17:39-58.

27. Donath MY, Shoelson SE. Type 2 diabetes as an inflammatory disease. Nat Rev Immunol 2011;11:98-107.

28. Mirza S, Hossain M, Mathews C, et al. Type 2-diabetes is associated with elevated levels of TNF-alpha, IL-6 and adiponectin and low levels of leptin in a population of Mexican Americans: a cross-sectional study. Cytokine 2012;57:136-42.

29. Neeland IJ, Turer AT, Ayers CR, et al. Dysfunctional adiposity and the risk of prediabetes and type 2 diabetes in obese adults. JAMA 2012;308:1150-9.

30. McLaughlin T, Lamendola C, Liu A, et al. Preferential fat deposition in subcutaneous versus visceral depots is associated with insulin sensitivity. J Clin Endocrinol Metab 2011;96:E1756-60.

31. van den Borst B, Gosker HR, Koster A, et al. The influence of abdominal visceral fat on inflammatory pathways and mortality risk in obstructive lung disease. Am J Clin Nutr 2012;96:516-26.

32. Kim JS, Le KA, Mahurkar S, et al. Influence of elevated liver fat on circulating adipocytokines and insulin resistance in obese Hispanic adolescents. Pediatr Obes 2012;7:158-64.

33. Esposito K, Nappo F, Marfella R, et al. Inflammatory cytokine concentrations are acutely increased by hyperglycemia in humans: role of oxidative stress. Circulation 2002;106:2067-72.

34. Pickup JC, Chusney GD, Thomas SM, et al. Plasma interleukin-6, tumour necrosis factor alpha and blood cytokine production in type 2 diabetes. Life Sci 2000;67:291-300.

35. Asakawa $\mathrm{H}$, Miyagawa J, Hanafusa $\mathrm{T}$, et al. High glucose and hyperosmolarity increase secretion of interleukin-1 beta in cultured human aortic endothelial cells. J Diabetes Complications $1997 ; 11: 176-9$ 